\title{
Estudos organizacionais críticos e pensadores nacionais
}

\section{Critical organizational studies and brazilian thinkers}

\author{
Ana Paula Paes de Paula ${ }^{1}$ \\ Universidade Federal de Minas Gerais, Faculdade de Ciências Econômicas, Departamento de Ciências Administrativas, Belo \\ Horizonte - MG, Brasil
}

O objetivo da chamada de trabalho que deu origem a este número temático era verificar o status da tradição autônoma dos estudos organizacionais críticos, fundamentada na influência exercida por pensadores nacionais nas pesquisas do campo, especialmente, Alberto Guerreiro Ramos, Maurício Tragtenberg e Fernando Prestes Motta.

O argumento desta chamada surgiu a partir de uma pesquisa realizada por esta editora (PAES DE PAULA, MARANHÃO, BARRETO et al., 2010), que constatou a existência de estudos organizacionais críticos no Brasil antes da emergência dessa corrente na Europa e nos EUA. Esses pensadores nacionais produziram estudos com essas características, que antecederam o advento do critical management studies e que são simultâneos aos trabalhos de origem francófona. A ideia central é que essa antecedência constitui uma tradição, que é autônoma porque a base teórica e epistemológica utilizada por esses pensadores críticos é distinta, e mesmo oposta ao pós-estruturalismo predominante no contexto internacional, uma vez que é humanista radical e se baseia no marxismo, no anarquismo, na teoria crítica e no existencialismo.

Os artigos recebidos para avaliação e composição do número confirmam a continuidade dessa tradição autônoma, cuja manifestação ocorre às margens do mainstream, como é de se esperar em relação à produção com viés crítico. Este número temático reafirma que o pensamento desses críticos nacionais foi intensamente semeado, de modo que floresceu e frutificou, gerando linhas de pesquisa consistentes que influenciam, pelo menos, duas gerações de pesquisadores. Considerando a busca por manter viva essa tradição, bem como sua autonomia, antes de apresentar os artigos que compõem este número temático, vale a pena fazer algumas considerações sobre a preservação e a disseminação de algumas práticas de cultivo científico, que reproduzem uma paisagem cada vez mais estandardizada nas áreas de administração e ciências sociais. A situação vem se agravando a despeito das críticas de Guerreiro Ramos (1958) à simetria, ao dogmatismo, ao dedutivismo, à alienação e à inautencidade da sociologia brasileira e das denúncias de Tragtenberg (1979) em relação à delinquência acadêmica e à decadência intelectual nas universidades.

É inegável o crescimento dos estudos organizacionais críticos nos últimos anos. No entanto, a paisagem se pauta por estândares e o solo acadêmico se mostra cada vez menos propício para o cultivo de artigos com abordagem crítica. Uma prova disso é que as editorias dos principais periódicos da área, com honrosas exceções, tratam as produções dessa natureza como flores exóticas. Tal como André Le Nôtre, o paisagista de Versalhes - com seu estilo de jardinagem que valorizava a perfeita ordem e simetria, simbolizando o auge da nobreza -, esses periódicos seguem padrões de avaliação que favorecem a aprovação de artigos

Artigo submetido em 1 de março de 2015 e aceito para publicação em 24 de abril de 2015.

${ }^{1}$ Doutora em Ciências Sociais pelo Instituto de Filosofia e Ciências Humanas/UNICAMP; Professora Titular da Universidade Federal de Minas Gerais. Endereço: Av. Antônio Carlos, 6627 - sala 4033 - FACE - UFMG, Pampulha, CEP 31270 - 010, Belo Horizonte - MG, Brasil. E-mail: appaula@face.ufmg.br 
elaborados de acordo com a linha de montagem que engendra o atual produtivismo científico. Artigos teóricos e ensaios, bem como estudos que recorrem a metodologias heterodoxas, que não se baseiam exclusivamente em evidências empíricas e recorrem à proposições especulativas - escapando às instruções do método hipotético-dedutivo e do objetivismo - são avaliados conforme diretrizes inadequadas e, por fim, recusados. Ideias que não se enquadram nos padrões paradigmáticos hegemônicos e no das descobertas da ciência normal são consideradas excêntricas e subversivas, ameaçando a ordem vigente nos jardins de Versalhes acadêmicos. Assim, são usualmente rechaçadas por editores e pareceristas, os quais evitam que venham à luz e sejam apreciadas, preservando a "harmonia" e a "nobreza" da paisagem.

Observa-se um terreno fértil para proliferação de trabalhos com múltipla autoria, que geralmente se apresentam de acordo com três tipos de padrão. Em primeiro lugar, temos a produção isolada, cultivada apenas para cumprir as exigências de publicação impostas pelos programas de pós-graduação, como requisito para obtenção de títulos e manutenção de bolsas de estudo, de modo que o autor publica um ou dois trabalhos com o orientador, ou com a equipe de pesquisa, atinge seus objetivos imediatos e abandona a carreira científica. Em segundo lugar, temos a produção descontínua, verificada quando o autor troca frequentemente de temática e abordagem, pois publica conforme as oportunidades e parcerias surgidas ao longo do caminho, uma vez que considera, diante das pressões por produtividade, que não devem ser desperdiçadas, de forma que não consegue manter a consistência dentro de uma linha de pesquisa. Finalmente, há a produção particionada, prática também conhecida como salami science (REINACH, 2013), porque nesse caso a equipe de investigadores recorre ao "fatiamento" dos resultados da pesquisa em diversos artigos, os quais, uma vez publicados, contribuem para inflacionar os pontos nos currículos Lattes. Nesse panorama, os livros estão deixando de ser uma opção válida para a comunicação científica, pois não são igualmente valorizados pelas agências de fomento, que inadvertidamente, ou não, estimulam o desmembramento de teses, dissertações e relatórios de pesquisa em artigos destinados para os prestigiosos e qualificados periódicos.

Neste contexto, pesquisadores que lavram, além do trabalho científico em equipe, uma carreira solo e autoral, estão perdendo espaço. Em primeiro lugar, porque suas produções reflexivas costumam ser recusadas em periódicos, que, como vimos, não privilegiam mais trabalhos teóricos e nem ideias que não reforcem o que já é conhecido, além de estabelecerem regras que dificultam a submissão desse tipo de texto. Alguns periódicos limitam excessivamente o tamanho dos artigos e exigem dos pareceristas que sejam cobradas citações de artigos mais recentes. Essas limitações, em um contexto no qual os pareceristas costumam solicitar que os autores atinjam o estado da arte do assunto de que estão tratando (requisito exigido como condição para acrescentarem qualquer ideia nova), tornam o exercício do ensaio praticamente impossível. A imposição da elaboração do estado da arte, que é monográfica e protocolar, desvia os autores dos seus reais objetivos e atribui um perfil escolar aos textos. A exigência de citações de trabalhos recentes, por sua vez, gera críticas dos pareceristas à utilização de textos tipicamente referidos em ensaios, os quais costumam ser mais antigos e clássicos, independentemente de sua qualidade e importância. Ademais, o tamanho exigido é insuficiente para o desenvolvimento de tal estado da arte e as linhas se esgotam antes das ideias do ensaio propriamente ditas serem exploradas. Em segundo lugar, produções com esse perfil não têm a periocidade de floração exigida para a manutenção dos padrões paisagísticos impostos pelas agências de fomento e pelos programas de pós-graduação, enquanto os livros, espaços que seriam adequados para este tipo de trabalho, como já vimos, não são devidamente valorizados.

De um modo geral, a progressiva massificação da pós-graduação em administração e a política de valorização excessiva da publicação em periódicos estimulada pelas agências de fomento, em um contexto de publish or perish, está se traduzindo em uma produção que fica devendo em relevância, originalidade e reflexividade (REGO, 2014). Por outro lado, esse ambiente mantém o solo hostil tanto à pesquisa quanto à produção acadêmica com viés crítico. Dessa forma, a oportunidade deste número temático é muito bemvinda, pois estimula o debate dos estudos organizacionais críticos nacionais e reafirma a sua vitalidade. Além disso, também possibilita, mais uma vez, um questionamento sobre o seu futuro: qual vai ser o espaço para o florescimento desse tipo de produção na paisagem descrita, cada vez mais predominante na ciência brasileira? Críticos costumam alimentar divergências externas e internas e já se tornou lugar comum dizer que seguem desunidos. Pouco tem sido feito do ponto de vista político e institucional para remediar essa 
situação, de modo que tais flores exóticas - que hoje aparecem solitárias e teimosas, destoando nos jardins versalhianos acadêmicos - podem estar seriamente ameaçadas de extinção.

Este número temático foi organizado em três blocos, que ilustram a dinâmica da tradição autônoma dos estudos organizacionais críticos no Brasil. O primeiro traz artigos sobre linhas de pesquisa inspiradas por Guerreiro Ramos. O segundo é composto de trabalhos que abordam linhas de pesquisa a partir da obra de Maurício Tragtenberg. O último apresenta textos fundamentados nas categorias e lógicas de pensamento de diversos pensadores e investigadores críticos nacionais.

No primeiro bloco, temos três artigos que são uma confirmação da continuidade da tradição autônoma dos estudos organizacionais críticos a partir do pensamento de Guerreiro Ramos, pois apontam a frutificação de suas ideias por meio da constituição de duas linhas de pesquisa bastante consistentes. Na abertura, Maurício Serva, Déris Caitano, Laís Santos e Gabriel Siqueira trazem o artigo "A análise da racionalidade nas organizações - um balanço do desenvolvimento de um campo de estudos no Brasil". Este artigo apresenta um levantamento da produção acadêmica sobre organizações inspirada pela leitura habermasiana feita por Maurício Serva do trabalho de Guerreiro Ramos em meados da década de 1990. No artigo, os autores constatam a expansão e o amadurecimento da linha de pesquisa sobre a racionalidade substantiva, que foi iniciada por este pesquisador. Em seguida, Gustavo Costa de Souza e Antônio Lima Ornelas apresentam o artigo "Alberto Guerreiro Ramos e a autonomia dos estudos organizacionais críticos brasileiros: esforços de uma trajetória intelectual", que, em homenagem ao centenário do nascimento do sociólogo baiano - que ocorre neste ano de 2015 -, resgata suas contribuições para o problema epistemológico da racionalidade nas organizações, em mais uma demonstração da consolidação da linha de pesquisa cultivada por Maurício Serva. O terceiro artigo, de autoria de Elinaldo L. Santos, Reginaldo Souza Santos e Vitor Braga, intitulado "A visão de Guerreiro Ramos sobre a administração do desenvolvimento: conceitos, contribuições e implicações", discute uma segunda linha de pesquisa baseada nas reflexões desse pensador, que envolve a questão do desenvolvimento no Brasil. Valendo-se de uma metodologia ainda pouco explorada na área, que é a história dos conceitos, os autores resgatam categorias elaboradas por Guerreiro Ramos para verificar suas implicações na administração do desenvolvimento.

No segundo bloco, temos dois artigos que comprovam a continuidade da tradição autônoma dos estudos organizacionais críticos brasileiros a partir do pensamento de Maurício Tragtenberg, cujo plantio estimulou a formação de linhas de pesquisas independentes e relevantes por diversos pesquisadores. O primeiro artigo, "A influência de Maurício Tragtenberg na obra da primeira geração de pesquisadores nos estudos organizacionais críticos brasileiros", elaborado por André Luís Marra do Amorim e Camila Brüning, constata que categorias tragtenbergianas foram levadas adiante nas linhas de pesquisas sustentadas por Fernando Prestes Motta, José Henrique de Faria e Fernando Coutinho Garcia, representantes de uma geração que valoriza o trabalho de natureza autoral e que disseminou suas ideias para inúmeros investigadores, numa demonstração de que a semeadura feita por Tragtenberg continua a ser replicada e insiste em sua florescência. O segundo artigo, "Continuidade Hegel-Marx? Solução especulativa em burocracia e ideologia para a relação entre Estado e sociedade no modo de produção asiático", é de Elcemir Paço Cunha, pesquisador da área que desenvolve desde seu doutoramento uma linha de pesquisa marxiana. Neste estudo, o autor questiona algumas elaborações tragtenbergianas, apresentando um posicionamento original que muito agradaria Maurício, um crítico do discipulado, que estimulava a independência de pensamento. Este artigo é um exemplar típico de flor exótica que costuma enfrentar resistência nas avaliações feitas pelos periódicos, de forma que sua presença neste número temático é bastante emblemática.

No fechamento deste número temático, temos o terceiro bloco, composto por dois artigos, incluídos por, de certa forma, darem continuidade à tradição autônoma dos estudos organizacionais críticos no Brasil. Embora não tenham os pensadores críticos nacionais como objeto principal do texto, esses artigos cultivam tal tradição, pois seguem categorias e lógicas de pensamento engendradas por esses autores. O primeiro artigo é "Silêncio organizacional: introdução e crítica", de Marcos Júnior de Moura Paula e Deise Luíza da Silva Ferraz, no qual os pesquisadores abordam o silêncio organizacional, uma linha de pesquisa bastante desenvolvida no contexto internacional. No entanto, tal como recomendaria Guerreiro, os pesquisadores realizam uma crítica da importação dessa temática e recorrem a ideias de outros pensadores nacionais, como 
Tragtenberg e Prestes Motta - além de pesquisadores estabelecidos nos estudos organizacionais críticos para denunciar o possível caráter opressor do conhecimento gerado por essa linha de pesquisa e desnudar as tentativas de naturalização das interpretações dos pesquisadores estrangeiros sobre o silêncio organizacional. O segundo artigo é "O sujeito na epistemologia lacaniana e sua implicação para os estudos organizacionais", de Ketlle Duarte Paes e Eloise Livramento Dellagnelo. Esse artigo representa a possibilidade de uma releitura do pós-estruturalismo, a partir da tradição autônoma dos estudos organizacionais críticos brasileiros. O texto não somente aborda uma problemática central para os pensadores nacionais, que é a questão do sujeito, como também trabalha a interface entre psicanálise e estudos organizacionais, explorada por Prestes Motta. As autoras inovam ao promoverem esse debate a partir de um referencial teórico não utilizado na obra desses pensadores, a psicanálise lacaniana, além de retificarem a ideia de morte do sujeito, que costuma ser erroneamente atribuída ao pós-estruturalismo. Por outro lado, também recorrem a algumas categorias criadas por Guerreiro nesse percurso, bem como dialogam com diversos pesquisadores nacionais do campo dos estudos organizacionais críticos, imbuídas de suas formas de pensar. Esse ensaio é um excelente fechamento para o número temático, pois significa mais uma floração tipicamente extravagante que persiste em perturbar a estandardizada paisagem acadêmica versalhiana.

É com prazer que convido os (as) leitores (as) para apreciarem os exemplares únicos deste número temático, exibidos neste espaço de exposição proporcionado pelos Cadernos EBAPE.BR Vale fazer um agradecimento especial ao professor Fernando Guilherme Tenório, um constante interlocutor e incentivador, por suas inúmeras contribuições aos estudos organizacionais críticos no Brasil. Também gostaria de expressar minha gratidão a Fabiana Braga Legal e Anderson Ricci, pela assistência solícita e compreensiva durante todos estes meses de trabalho. Aproveito, ainda, a oportunidade para convocar os críticos de todas as tendências para a urgente missão de preservamos nossos jardins suspensos da Babilônia. Diferentemente dos jardins de Versalhes, os jardins da Babilônia, cujas flores e frutas exóticas vicejavam em pleno deserto, têm uma existência cercada de mistério e foram construídos para recriar o habitat natural das montanhas das quais Amytis, esposa de Nabucodonosor, sentia saudades. Contam as lendas que, nestes jardins, heróis e vilões se enfrentavam pela transcendência do eu e pela conquista de novos mundos. Utopia? Com certeza, embora não pareça ser casual, pois Amytis é um nome persa cuja tradução é "ter um bom pensamento". E o pensamento que me ocorre é o resgate da "formosa liberdade", que um dia Antônio Cândido viu no trabalho acadêmico do jovem Maurício Tragtenberg.

\section{Referências}

GUERREIRO RAMOS, A. A redução sociológica. Introdução ao estudo da razão sociológica. 2. ed. Rio de Janeiro: Tempo Brasileiro, 1965. Originalmente publicado em 1958.

PAES DE PAULA, A. P. et al. A tradição e a autonomia dos estudos organizacionais críticos no Brasil. Revista de Administração de Empresas, v. 50, n. 1, p. 10-23, 2010.

REINACH, F. Darwin e a prática da "Salami Science". O Estado de São Paulo, São Paulo, 27 abr. 2013. Disponível em: 〈http://sao-paulo.estadao.com.br/noticias/geral,darwin-e-a-pratica-da-salami-science-imp-,1026037>. Acesso em: 28 fev. 2015

REGO, T. C. Produtivismo, pesquisa e comunicação científica: entre o veneno e o remédio. Educação e Pesquisa, v. 40, n. 2, p. 325-346, 2014.

TRAGTENBERG, M. A delinquência acadêmica: o poder sem saber e o saber sem poder. São Paulo: Rumo Gráfica Editora, 1979. 